\title{
Interethnic Relations between ESL Students
}

\author{
Yoko Kobayashi \\ Faculty of Humanities and Social Sciences, Iwate University, \\ Morioka, Japan
}

This study is part of a larger investigation into Japanese students' use of English and friendship buildup inside and outside Canadian English as a second language (ESL) institutes. Both qualitative and quantitative data were garnered primarily from formal in-depth interviews with nine Japanese students and questionnaire surveys with 216 students. Based on the data, the present study explores Japanese students' friendship with Korean students, large numbers of whom are enrolled in ESL schools in English-speaking countries. The study provides evidence of the frequent opportunities for members of these two groups to communicate with each other, which sometimes leads to Japanese students' overgeneralised positive perceptions of Koreans as a whole. Also documented are the varying impacts of Korean students' references to Japan's war-time invasion of Korea upon Japanese students, ranging from appreciation of this new knowledge to the development of negative perceptions of Korean students. Furthermore, the study reveals that the combination of quantity and quality contact can cause the formation and consolidation of bonding between Japanese and Korean students, which then opens up a historically sensitive dialogue without jeopardising their long-term relationship.

Keywords: overseas study, ESL, interethnic relations, Japan, Korea, history

\section{Research Background}

\section{Literature review}

The multibillion-dollar English as a second language (ESL) industry dwarfs all other foreign-language teaching worldwide, including foreign-language study abroad in non-English-speaking countries, but the lack of research into the industry is in startling contrast to the increasing body of literature on the study-abroad experience of native English-speaking, predominantly American students mainly in Spain, France or Mexico (Allen \& Herron, 2003; Dolby, 2004; Freed, 1995; Kinginger, 2004; Schmidt-Rinehart \& Knight, 2004; Talburt \& Stewart, 1999; Wilkinson, 1998, 2001, 2002). In spite of the limited market size of study abroad-programmes catering to native speakers of English, those researchers are well aware of the need to explore the effect of study abroad on students' linguistic, cultural and affective growth and call for more research: 'Study abroad (SA) is an integral part of foreign language (FL) students' academic experience, yet surprisingly little is known about its linguistic and affective ramifications' (Allen \& Herron, 2003: 370); 'Despite the growth in the number of U.S. students studying abroad, and study abroad's increasingly common place in U.S. universities' globalizing rhetoric, actual research on study abroad participants is quite limited' (Dolby, 2004: 153). 
The irony is that the most popular study-abroad context in the world is the least explored. This context is provided by non-credit, private ESL institutes in English-speaking countries catering to nonimmigrant, international students. The similarly neglected research theme is the most common type of communication for those students: interactions among non-native English-speaking students enrolled in the same schools. This surprising disproportion between the magnitude of the ESL industry in English-speaking countries and the paucity of scholarly research on the context has remained unchanged and unnoticed for decades.

It is true that there have been a number of study-abroad studies conducted in English-speaking countries, for example, focusing on Japanese high school or university students' linguistic and affective adjustment at local high schools or universities (Crealock et al., 1999; Toyokawa \& Toyokawa, 2002; Yashima et al., 2004). What have yet to be part of such literature are studies conducted at private ESL schools with a specific focus on those students' interactions with other schoolmates. Instead, international students' communication with host nationals such as local high school/university students and host families continues to be the focus in many studies, with an attempt to identify factors that can predict frequency of communication with host nationals. Toyokawa and Toyokawa (2002: 365-366) are correct in pointing out:

To date, however, most studies on this topic [international students' friendship buildup on and off campus] have been conducted with Caucasian, full-time students in four year colleges (Terenzini, Pascarella, \& Blimling, 1996); indeed, few studies have examined other groups of students, including international students, regarding activities and life in out-of-class contexts. One of few exceptions is a study conducted by Bochner, McLeod, and Lin (1977).

Bochner's Functional Model of Friendship Networks (Bochner et al., 1977; Ward, 1996; Ward et al., 2001) is worthy of reiteration here as the model categorises international students' potential friends into three groups: co-nationals, host-nationals and noncompatriot foreign students, and presupposes that '[the pattern of friendship among foreign students] affects practically all of the sojourner's social relations and attitudes' (Bochner et al., 1977: 278). Bochner and his colleagues empirically confirmed that international students engage in those three types of friendship networks and that each of the networks provides students with important yet different functions. The model's frequent appearance in related recent studies on international students' friendship networks, on the other hand, serves as evidence in itself of the continuance of our limited knowledge of international students' interactions with co-nationals or other L2 international students on and off campus even in contexts where opportunities for such friendship are ample. Referring to the Canadian research context, for example, Smith and Schneider (2000: 248) state: 'Given the multitude of different ethnic groups that coexist in various regions of Canada, it is surprising that so few studies have been carried out on inter-ethnic relations'. The present explanatory study, part of a larger-scale main study, intends to fill the gap, drawing on theories of intergroup relations (Giles et al., 1977; Gudykunst \& Kim, 2003; Stephan, 1999; 
Taylor \& Moghaddam, 1994). Theoretical discussions are incorporated into analyses of results.

As pointed out above, the field of TESOL and ESL/EFL acquisition research continues to focus on international ESL students' friendship network with host nationals. Those studies, therefore, provide incomplete findings on international ESL students' use of English with other non-native international students and their mutual friendship development. That said, a growing body of longitudinal ethnographic studies on the children of non-Englishspeaking immigrants in mainstream classrooms has helped gain a better understanding of quality as well as quantity in international students' friendship with co-nationals. Those interpretive studies, conducted through participant observation and in-depth interviews, are entrenched in classroom contexts and have contributed greatly to illuminating those students' difficulty in making friends with host nationals and their limited friendship network with co-nationals (McKay \& Wong, 1996; Miller, 2004; Pon et al., 2003).

For instance, Miller (2004), in a three-year study of 10 high-school students newly immigrated into Australia with their parents, depicts Chinese and Bosnian students' adaptation to mainstream schools and contact with local Australian students. The study shows that the presence of many other Mandarin-speaking students and their sense of identity as Chinese reduce their perceived need to speak English. A shocking finding from Miller (2004) is that all six Asian students made little progress in English after a few years in Australia and three of them made no mainstream Australian friends even after five years. In the case of Tina, a Taiwanese girl, her friendship network continues to consist of Mandarin-speaking students exclusively and her English is 'still a barrier to success in some academic subjects' (Miller, 2004: 311). Interestingly, Tina remarked that she used English more to interact with other ESL students in an on-arrival intensive ESL programme for new ESL students coming from all over the world than at her current high school where over 550 out of 650 students speak English as L1 at the school and Chinese ESL students there have abundant opportunities to interact with monolingual speakers of Australian English. This remark suggests the advantage of studying English in multilingual, multicultural and multiracial ESL programmes where students are all non-native English learners, whereas in mainstream school settings some ESL students are made to feel marginalised in the presence of mainstream students and reportedly develop a sense of racial discrimination such as they 'don't like the "black hairs"' because 'If we [Tina and her new classmate from Bosnia] go to (a mainstream) class together, they, they know that she is not Australian, don't speak much English, but go to talk to her not me' (Miller, 2004: 303).

The linguistically, culturally and ethnically international population of ESL schools in English-speaking countries can serve as a significant contributor to providing students with the chance to engage in intercultural communication in English. The sheer presence of students from Asia can also play an innovative role in communicating both the diversity and commonalities in Asia to students of various backgrounds. On the other hand, international conflict, for example between Arab countries, most recently Iraq, and the USA and its allies is reported to expose Muslim students to unjustified 
discrimination in educational settings (Miller, 2004). Researchers have yet to explore ESL school settings from the perspective of interethnic relations, unlike the extensive research on prejudice continuously conducted in the USA to improve race relations at school, mainly between Whites and African-Americans, and other US-born minority students (Stephan, 1999).

Based on the literature review of second-language learning research and intergroup relations theories, this study conceptualises Japanese study-abroad students not only as language learners expected to learn the target language from teachers and host families but also as individuals and group members dealing with intergroup relations in a second language. More specifically, by positioning ESL institutes catering to international students as an ideal site for intercultural communication among non-native speakers of English, the present study explores the relationship between Japanese and Korean students, who comprise the two largest groups at many ESL institutes in North America. As research questions, the study examines the frequency of communication between the two group members, the types of communication patterns and Japanese students' perceptions about their experience.

\section{Pilot study}

Identifying both Japanese and Korean students as majority groups at many ESL institutes in English-speaking countries, a pilot study explored the issue of mutual friendship buildup between the groups in order to determine the significance of pursuing the research issue further in the subsequent main study, which aimed to identify factors influencing Japanese students' intercultural communication in L2 inside and outside the school setting during their overseas study. The small-scale pilot study was conducted from summer 2003 to spring 2004, entailing mail surveys to and interviews with Japanese marketing/coordinating/counselling staff at Canadian ESL schools. The qualitative data garnered from 11 Japanese staff indicated that interethnic issues between Japanese and Korean students were significant. For instance, the following two written comments are indicative of the existence of interethnic conflict:

I do not see any particular problem with Japanese students' interaction with Chinese students. They both are considerate for the mutual communication by showing respect and adjusting their communication styles. However, I often notice that some Korean students have a very strong anti-Japanese sentiment. It seems that Japanese students try to be careful to avoid bringing up bilateral political and historical issues. There are some Japanese students who are shocked to confront Korean students' anti-Japanese feeling.

Japanese and Korean students have no problem getting along with each other. In fact, there are cases of Japanese students spending more time with Korean students than with other students. Quite a few Japanese students say that their [negative] perspectives of Korean students have changed. However, there are other Japanese students who come to dislike Korean students as some Korean students always bring up 
war-time stories. In many cases, Japanese students do not try arguing and just let it go whatever Korean students say.

While Japanese staff are important in the ESL teaching context and their voices, however limited, should be respected, the pilot study failed to garner students' perspectives. The main study will present those critical voices.

\section{Sociopolitical relations between Japan and South Korea}

As often exemplified in relations between Whites and African-Americans in the USA and Anglophone and Francophone Canadians, empirical research and theoretical arguments on intergroup relations ascertain that in order to explain the present state of relations between two social groups, it is useful to keep in mind the past history of their relations' (Taylor \& Moghaddam, 1994: 198). This section describes the sociopolitical and historical background of interethnic conflicts between Japan and Korea, which, as suggested in the pilot study, seem to be an integral part of the relations between students from the two nations.

The end of WWII in 1945 represents defeat for Japan but liberation from Japanese occupation for Korea and other Asian nations. Any sense of mutual ties between Japanese and Korean citizens had to wait until international events such as the 1990 Seoul Olympics and the 2002 World Soccer Game co-hosted by the two nations. Japanese citizens are now developing cultural curiosity about Korea, and the growing interest in Korea and Korean culture among the Japanese young generation has become more than a fad, consolidated by the spread of the recognition that Korea is a nation of civilisation and 'cool' pop culture. Young Japanese people's new perspectives of Korea are frequently featured in the Japanese and overseas media (Brasor, 2004; Yamaguchi, 2004).

Those new perceptions of Korea by young Japanese people, however, are often based on their limited knowledge of the war history between the two nations, due to the quality and quantity of those historical facts communicated to Japanese students at school. History textbooks approved by the Ministry of Education and used at Japanese schools are denounced by the Korean Government as deliberately repudiating, moderating or justifying the atrocities of the Japanese Imperial Army during WWII and cultivating in the Japanese young generation a feeling of superiority over other Asian countries (Nelson, 2002; Rozman, 2002; Song, 2000; Tawara, 2000). This condemnation by Korea is commonly perceived or dismissed by not a few Japanese lawmakers and voters as interference in Japanese national affairs. This unchanged situation in Japan has been a source of anti-Japanese sentiment in Korea, where the teaching of history is prioritised, producing young Korean students who are well informed of the indignity and mortification their senior generations have been subjected to, and firm in their ethnic identity and national pride.

There remain other historical and political issues affecting the strength of civic-level exchanges between Japanese and Koreans and the growth of mutual understanding and respect. Those unresolved issues include: Japanese lawmakers' official visits to the Yasukuni Shrine which honours the war dead, 
including war criminals, a series of statements made by a succession of Japanese politicians over 'positive' aspects of the Japanese Army during WWII (e.g. the introduction of disciplined public education and establishment of civil infrastructure), the role the late Japanese (Showa) Emperor played in the War (whether a commander or a puppet), the necessity for the Japanese Royal Family to announce their official apology for those who suffered from the war-time exercises by the Japanese Army, the accurate size and intensity of destruction caused by the Japanese Army in Asia, the Japanese Government's political stance on Korean 'comfort women', 'disposable miners' and anyone whose life was lost or irreparably impaired, and Tokyo's political decisions on compensation for those people and on measures to restore their nationalities and dignity. Territorial and trade issues also continue to destabilise Korea-Japan relations.

\section{The Study}

\section{Participants}

The findings and discussion in the present study are based on research conducted at a total of seven schools located in Canadian urban areas in the latter part of 2004. Nine Japanese students participated in interview sessions and 216 in questionnaire surveys. Interviewees' demographic information appears in the following section along with their narratives. The survey respondents consist of 159 females $(73.6 \%)$ and 57 males $(26.4 \%)$ with an average age of $21.99(\mathrm{SD}=5.37)$ who were studying at school for 7.89 weeks on average $(\mathrm{SD}=8.96)$. Students' perceived English proficiency, which was measured by five items (Cronbach's $\alpha=0.77$ ), met the assumption of normal distribution, an indicator of variances in students' English proficiency. Each part of the study was conducted after gaining formal consent from the directors of the ESL institutes.

\section{Procedure}

The present study is part of a larger investigation into 'Japanese overseas ESL students' studying and living experience'. The main research theme was clearly stated in Japanese in a questionnaire cover sheet and a letter of invitation for interview sessions. The questionnaire survey was conducted either by a group administration method or by a take-home method. The response rate to the Japanese questionnaire was $74-100 \%$. The detailed description of item validation is not provided here because this study focuses on open-ended questions. One point to be mentioned here is that although the investigation into the existence and degrees of interethnic conflict between Japanese and Korean students was part of the study, it was not made explicit under the main research theme. For example, part of the open-ended section, which is examined in detail in this study, inquires about Japanese students' experience with making friends with Korean students and the frequency of such opportunities and yet the inquiry is embedded in other themes, which can be translated into some degree of disguise and decreased face validity. 
Taped interview sessions were conducted in Japanese and lasted from 2 to 4 hours, mostly 2 hours. In the case of seven students from three schools, the researcher met them in person only after having directors or teachers choose candidates willing to participate in the sessions and gaining their formal, written consent. An exception was two students from one school where a 5-week participant observation was conducted. The observation process enabled the researcher to observe students' friendship networking and engage in casual talks with Japanese and other students during lunchtime and orientation sessions. The observation was recorded as case study notes.

\section{Data analysis}

First, frequency analysis was performed on students' written responses to one of the open-ended inquiries in the questionnaire, 'Did you encounter students from South Korea at your school?'; 'If so, did you find it easy to get to know them?' The analysis largely produced affirmative, neutral, and negative categories of responses. Second, in order to examine to what extent the threefold categorisation would be relevant to another type of data, an exploratory pattern-matching technique was employed with the interview data. Concurrently, as a third source of evidence, the above-mentioned case study database was subjected to the same analysis. Students' written responses and taped interview data presented in the subsequent sessions are translated from the original Japanese data.

\section{Limitation}

The major limitation of this study, which readers are advised to be alert to through this paper, is the fact that Korean students' voices and perspectives are categorically missing in the data set, which presents solely Japanese students' voices. This limitation is not due to inability to access Korean students in the research contexts but merely due to the researcher's inability to speak Korean. Given that many ESL students, in particular the ones from Asia, have a relatively limited, beginner-level English, it was judged crucial to conduct questionnaire surveys and interview sessions in students' L1. Although it was feasible to have ESL staff conduct an English questionnaire survey with Korean students, it was decided not to because of their varying English writing levels, the importance of their unhindered writings in L1, an uncertain impact of the researcher - a Japanese female interested in learning about their perceptions about other Japanese students - upon their responses, and no feasibility of conducting follow-up interview sessions in Korean language. Furthermore, the researcher opted not to raise this issue at the site of participant observation and instead engaged in casual conversations with Korean students in English, mostly learning about our pop culture and the English education system. 


\section{Findings}

\section{Pleasant friendship}

Ninety-eight students out of 216 (45.3\%) have made friends with Korean students or identified Korean students as a group of people whom they find easy to approach and get acquainted with. Comments were identified that can be interpreted as overgeneralised positive perceptions of Korean students such as 'Korean students are all gentle' and 'They are all kind and friendly'. Regarding nine interviewees, seven participants remarked on their pleasant friendship with Korean students (two of them emphasised individual aspects instead of group boundaries during the interview sessions). Responses from Japanese students appear to suggest that opportunities to engage in communication with Korean students are far more frequent than those with any other international students and that most Japanese students develop their closest friendships with Korean students. One 24-year-old male student, who moved up from the second-lowest level to the second-highest during the year and had a wide spectrum of friendship networks with his school mates and friends at other schools, sounded particularly certain about this point during the interview:

The fact is that the first friend Japanese students make is with a Korean. I believe any Japanese student would say so at whichever school you ask this question. I am sure about this. I think 100 out of 100 students would say so. As you know, we are Asians and we live in Asian society. It is so easy for Korean and Japanese students to be friends. My first friend was also a Korean.

$23.1 \%$ or 50 out of 216 students remarked that they simply met few chances to interact with Korean students, a response commonly made by a group of students from the same university in a custom-designed short-term special programme and also by one 26-year-old female interviewee, who attributed her difficulty with friendship buildup to her introverted personality, beginnerlevel English, her age (slightly higher than the average age, 21.9), and so on.

Japanese respondents' own reasoning behind the readiness among Japanese and Korean students to engage in mutual communication includes the sheer presence of each other's outgroups and the proximity in geographic location, cultures, ways of thinking/speaking, physical appearance and languages. The significance of those factors in intercultural communication is demonstrated in both theoretical arguments and empirical evidence (Babiker et al., 1980; Giles et al., 1977; Giles \& Byrne, 1982; Gudykunst \& Kim, 2003). Also mentioned are the recent dramatic increase in cultural exchange and the consequent interest in and knowledge of mutual pop culture, a command of Japanese/Korean language, and family members living in Korea. The development of Japanese and Korean students' sense of being Asian is understandable in the multiracial, multiethnic milieu of ESL institutes that admit international students from around the globe, including European students who are racially, linguistically and culturally very different from Japanese or Korean students. 


\section{Deeper friendship}

In-depth interviews with Japanese students reveal another finding that the questionnaire survey failed to capture: that the combination of quantity and quality contact can cause the formation and consolidation of bonding between Japanese and Korean students, which then opens up a historically sensitive dialogue without jeopardising their long-term relationship. One of the interviewees, the Japanese long-term male student mentioned above, is the only respondent in this category:

Back then I didn't know anything about it [the issue] at all. Who could know so much, for instance, about the issue of how Koreans are educated? Right? Then after I came here and I made friends with Korean students, we came to eat out together, have a chat, and as you can imagine, our topics unintentionally moved to the issue of Japanese education as they are interested in this topic. Then, while engaging in this topic, naturally that topic comes up and they ask like, 'We are taught like this at school. Is it true?' The only thing I can say to them is, 'We aren't taught,' right? I feel like showing them Japanese textbooks because such issues are covered in less than one-page, right?... As far as my Korean friends are concerned, their stance is, it'll be all right as long as we continue to get along with each other. So, it's not to 'forget' but to 'forgive' for them. And for us, it is to 'admit' and 'accept,' right? Do you see my point? We talk about these things together.

The communication between him and his Korean friends was still maintained at the time of interviews although it had been several months since some of those Koreans returned home. He was the only interviewee who remarked on the establishment of this stronger relation with his Korean friends to the point that they forthrightly engaged in sensitive issues. An item inquiring about having such candid dialogue with Korean students was not included in the questionnaire survey because neither the literature review nor the pilot study pointed to the possibility of such relations between Japanese and Korean students who study at overseas ESL schools mostly for a relatively limited period of weeks in the manifest presence of their own ethnic group members. Another initial concern was that such an item might 'potentially elicit a defensive reaction in the respondent', falling into the category of 'threatening behavioral questions' (Mertens, 2005: 188).

\section{Individual differences-oriented relationship}

Six percent or 13 students and two of nine interviewees noted that friendship buildup with Korean students depended on the individual or that they were not aware of differences in nationalities. Furthermore, 19.4\% or 42 out of 216 students provided rather vague responses such as 'so-so' with five students making no responses.

As implied by one written comment 'It is hard to get to know Korean students as they are always in their own group', the manifest existence of their own ethnic group can incline some group members to socialise with each other more often than with visibly similar yet linguistically and ethnically different 
other group members. The five-week participant observation conducted at a relatively mixed school reveals that new students tend to get acquainted with each other during the first orientation session and maintain this socialisation even after being assigned to different classrooms. This tendency was found in many international students at the school. Those Japanese and Korean students who readily found other co-nationals in every group of new students were predisposed to get acquainted with other co-nationals first. Throughout participatory observation in the cafeteria, two groups of Japanese students and Korean students were observed to occupy two different tables and communicate exclusively with each other.

An informal conversation during the participant observation with Japanese ESL students demonstrates, however, that some students are capable of moving beyond ethnic boundaries. A case in point is a Japanese male student who talked with the researcher for more than one hour during and after the lunch break. He appeared confident in stating that his extrovert nature and his previous experience of travelling abroad, studying in the USA and having American friends in Japan differentiates him from other Japanese students in that he could readily move from group to group on his own and make good friends with Korean students and other L2 students. Although limitations of space preclude further discussion of this point, one can note that his remark, other participant observation and variances in the interviewees (including a female struggling to make any friends mentioned above) suggest that individual-level elements significantly influence the extent to which students can benefit from ample opportunities for international communication.

\section{Lack of interest, defence and displeasure}

The opposite responses were fewer by far, with only 13 of 216 students $(6.0 \%)$ being unambiguous about their lack of interest in or difficulty in getting acquainted with Korean students. In this category was one 20-year-old female who socialised exclusively with her Japanese peers while explicitly expressing her lack of interest in non-European culture and people.

Furthermore, the questionnaire survey identified no more than one student who, due to her knowledge of the war-time history and the Korean people's deep-rooted animosity toward Japan, opted to avoid Korean students altogether by resorting to an avoidance style of conflict management (Gudykunst \& Kim, 2003). Her written response says: 'Although there are many Korean students at school, I have never thought of getting acquainted with them because the historical confrontation between the two nations is always in my mind.' One opposite response might be worthy of mention here as another different possibility that historical knowledge might be able to increase some other Japanese students' interest in discussing the issues with Korean students. One student notes:

I had almost no chances to speak to Korean students. But I wanted to become friends with them and discuss issues such as the Yasukuni Shrine [which honors the war dead, including war criminals], history education and war. Of course I also wanted to talk with Chinese students. 
Her wish was not realised mainly due to the fact that she was participating in a special programme organised by her university in Japan and designed for the university's summer programme by the ESL centre in Canada.

Even though Japanese staff in the pilot study mentioned Japanese students' frequent encounters with some Korean students eager to introduce the historical issue, as quoted earlier, this study identified only two students who specified their experience, which might relate to the issue of threatening behavioural questions mentioned earlier. One student responded to the openended inquiry by writing, 'I have many Korean friends. Many of them are nice, but there are some who are mean (ijiwaru). I was accused of (semerareta) responsibility for the historical things ... But basically, I like Korean students.' One 27-year-old, long-term female interviewee provided a far more detailed narrative based on her experience, observation and the new knowledge she had gained about for example the military draft system and the state of history education, which she had acquired from her 'many' 'loving' Korean friends during the past 11 months:

Such [war-time] issues have been drummed into (tatakikomareru) Koreans since their childhood. Like, Japan did these things to Korea. And, once Korean boys start to talk, nothing can stop many of them. And, ah, like on the Net, I was shown many things with their telling me that many horrible (hidoi) things like these happened. I was like, 'Oh ..., I see...' (ha-, sounannda-). Really, for sure, part of me was very surprised. Yet, many other young [Japanese] people go like, 'How obsessive!' (mo-, shitukoi-), 'It bothers me to be told something like that.' (sonnnakoto iwaretemo komaru), and 'How annoying!' (Urusa-i). That situation... Although Japanese and Koreans are easy to get along with each other, that kind of situation sometimes ... yeah...

I don't think Koreans would say such things so much to someone they aren't so close to. This is from my experience. And if we say, 'I don't know,' then they would explain more and more. I was listening throughout. And, ah, when I was shown lots of pictures on the Net, really shocking (sugoi) ones, I went like, 'I can't take it anymore, I really can't take it anymore' (givu attepu, givu attepu)... Really, [those picture were] beyond description (chottto mou sugoi...). Yeah, it was when I came over to my [Korean] friend's place...

There are surely some Japanese who have their opinions on these matters. Once Koreans start to talk with those Japanese, yeah . . Koreans are strong at making arguments. It sometimes happened that even when we were having a good time at a party those arguments turned the merry atmosphere into a hostile one.

She commented that she occasionally experienced such a tense atmosphere both in classrooms and outside the school setting. The cases of these two students, however limited, are important in that they did not resort to overgeneralisation even when challenged by some Korean students over the war-time issues. 


\section{Discussion and Conclusions}

This study found that the degree of susceptibility emanating from interethnic encounters varies among relatively young Japanese students, ranging from lack of interest, vulnerability, pleasure, a sense of learning and finally to awareness-raising about Korean people's negative feelings toward Japan and Japanese people. The following discussion attends to Japanese students' cooperative and conflicting contact with Korean students.

First, Japanese students' intensive encounters with Korean students induced many Japanese students to develop strongly positive perceptions of Korean students as a whole. Although such frequent opportunities to engage in individualised contact with Korean students automatically increases the possibility of encountering some Korean students who aspire to challenge Japanese students with the war-time issues, Japanese students' favourable perception of Korean students was found to be maintained when those challenging Korean interlocutors were differentiated from many others.

In addition, the present study identified one case in which personalised interactions with outgroup members lead to the realisation of mutual acceptance not only as individuals but also as outgroup members, a result also evidenced in Devine (1989) and Brewer (1994). That is, Japanese and Korean students who accumulate months of individualised contact in personal settings after school can increase both the quantity and quality of contact, which then raises the possibilities of developing stronger, more solid friendship and of engaging in discussions on the past and future of their nations. This suggestion, however, poses another issue concerning the friendship among international students at ESL schools: the significance of quality and quantity of contact automatically places short-term students at a disadvantage. The issue of friendship at the commercially flourishing yet academically unexplored educational terrain of ESL schools deserves more attention as short-term students are the majority during holiday seasons and stressreduced interactions among international students are essential for linguistically, culturally and psychologically successful overseas study regardless of its length.

In contrast, an occasional exposure to war-time histories through frequent interpersonal contact with Korean students was found to cause some other Japanese students' negative perceptions of Korean people. These contrasting cases show that intensive encounters with outgroup members can cause the development of both overtly positive and negative images of all those members. The possibility of negative perceptions of themselves held by other international friends or the development of negative perceptions of ethnic group members remains overlooked among researchers studying international students despite such development's conceivably undesirable impact on students' willingness to communicate with key figures during study-abroad experience.

In the case of some Korean ESL students' outspoken style, it is conceivable that perceiving the strength of their own ethnic group, the unsolved agonising interethnic conflict and historical issues, and the limited length of their enrolment in ESL programmes, some Korean students feel less hesitant to 
challenge Japanese students with interethnic issues. Compared to the longterm period of study required for international students in postsecondary or graduate programmes, the length is short-term for many ESL students at noncredit ESL institutes. The fact that a majority of students at ESL institutes are unlikely to be in the same school for a long time might lessen some students' sense of inhibition in bringing up thorny issues in the contexts of classrooms.

The present study implies that international students' intercultural, interethnic communication with other students in overseas study contexts is potentially influenced not only by individual factors such as personality, previous study-abroad experience and L2 proficiency, i.e. the traditional research focus in the domains of intercultural communication and secondlanguage learning, but also by sociopolitical issues and beliefs strongly held by students such as their perceptions of other groups, educational background, knowledge of other countries and those countries' educational systems, expectations of other groups' attitudes toward them, and perceived costs and/or rewards expected from interacting with other group members. The historical relations between/among groups in contact also exert a significant influence on their mutual perceptions and interactions.

Given the continued popularity of study-ESL-abroad programmes and the multicultural dynamics surfacing in this environment, it is vital for educators and staff members to raise awareness of the latent interethnic factors influencing students' intercultural communication in English. One suggestion is to employ more cooperative learning. Such learning, confirmed to be effective primarily by intergroup relations research, is now drawing attention from second-language educators (Ehrman \& Dörnyei, 1998). Although extant research on intergroup relations corroborates that cooperative learning does not necessarily change learners' perceptions of other groups as a whole (Stephan, 1999; Taylor \& Moghaddam, 1994), personalised interactions with other group members should become lifetime opportunities for relatively short-term ESL students from all over the world to get to know each other. In addition to greater introduction of cooperative learning into classrooms, ESL programmes, which commonly adopt the English-only policy and class size management by nationalities to facilitate students' use of English, can go one step further and enhance intergroup contact by, for instance, incorporating lunchtime into school activities and providing mixed group members with assignments that require after-school contact and interaction. Students' overseas study is the constellation of daily experience inside and outside classes. Students' engagement in personalised contact, mediated and endorsed by the school, should be able to foster the most effectively interpersonal and intergroup interactions in the target language.

\section{Acknowledgements}

This study is financed by a Japanese Government Grant-in-Aid for Scientific Research. I would like to thank the anonymous reviewers for their constructive comments on an earlier draft of this paper. My deepest gratitude is for all the Japanese students who agreed to participate in this study and shared with the researcher their experiences. 


\section{Correspondence}

Any correspondence should be directed to Associate Professor Yoko Kobayashi, Faculty of Humanities and Social Sciences, Iwate University, 3-18-34 Ueda, Morioka, Iwate, 020-8550 Japan (yokobaya@iwate-u.ac.jp).

\section{References}

Allen, H.W. and Herron, C. (2003) A mixed-methodology investigation of the linguistic and affective outcomes of summer study abroad. Foreign Language Annals 36 (3), 370-385.

Babiker, I.E., Cox, J.L. and Miller, P.M. (1980) The measurement of culture distance and its relationship to medical consultation, symptomatology and examination performance of overseas students at Edinburgh University. Social Psychiatry 15, 109-116.

Bochner, S., McLeod, B.M. and Lin, A. (1977) Friendship patterns of overseas students: A functional model. International Journal of Psychology 12 (4), 277-294.

Brasor, P. (2004) Korean wave may help erode discrimination. The Japan Times. Sunday, June 27. On WWW at http://www.japantimes.co.jp/cgi-bin.

Crealock, E., Derwing, T.M. and Gibson, M. (1999) To homestay or to stay home: The Canadian-Japanese experience. TESL Canada Journal 16 (2), 53-61.

Dolby, N. (2004) Encountering an American self: Study abroad and national identity. Comparative Education Review 48 (2), 150-173.

Ehrman, M. and Dörnyei, Z. (1998) Interpersonal Dynamics in Second Language Education: The Visible and Invisible Classroom. Thousand Oaks, CA: Sage.

Freed, B.F. (ed.) (1995) Second Language Acquisition in a Study Abroad Context. Philadelphia: John Benjamins.

Giles, H., Bourhis, R.Y. and Taylor, D.M. (1977) Towards a theory of language in ethnic group relations. In $\mathrm{H}$. Giles (ed.) Language, Ethnicity and Intergroup Relations (pp. 307-348). London: Academic Press.

Giles, H. and Byrne, J.L. (1982) An intergroup approach to second language acquisition. Journal of Multilingual and Multicultural Development 3 (1), 17-40.

Gudykunst, W.B. and Kim, Y.Y. (2003) Communicating with Strangers: An Approach to Intercultural Communication. New York: McGraw-Hill Companies.

Kinginger, C. (2004) Alice doesn't live here anymore: Foreign language learning and identity reconstruction. In A. Pavlenko and A. Blackledge (eds) Negotiation of Identities in Multilingual Contexts (pp. 219-242). Clevedon: Multilingual Matters.

McKay, S. and Wong, S.L. (1996) Multiple discourses, multiple identities: Investment and agency in second-language learning among Chinese adolescent immigrant students. Harvard Educational Review 66 (3), 577-608.

Mertens, D.M. (2005) Research and Evaluation in Education and Psychology: Integrating Diversity with Quantitative, Qualitative, and Mixed Methods. Thousand Oaks, CA: Sage.

Miller, J. (2004) Identity and language use: The politics of speaking ESL in schools. In A. Pavlenko and A. Blackledge (eds) Negotiation of Identities in Multilingual Contexts (pp. 290-315). Clevedon: Multilingual Matters.

Nelson, J.K. (2002) Tempest in a textbook: A report on the new middle-school history textbook in Japan. Critical Asian Studies 34 (1), 129-148.

Pon, G., Goldstein, T. and Schecter, S.R. (2003) Interrupted by silences: The contemporary education of Hong-Kong-born Chinese Canadians. In R. Bayley and S.R. Schecter (eds) Language Socialization in Bilingual and Multilingual Societies (pp. 114-127). Clevedon: Multilingual Matters.

Rozman, G. (2002) Japan and Korea: Should the US be worried about their new spat in 2001? The Pacific Review 15 (1), 1-28.

Schmidt-Rinehart, B.C. and Knight, S.M. (2004) The homestay component of study abroad: Three perspectives. Foreign Language Annals 37 (2), 254-262.

Smith, A. and Schneider, B.H. (2000) The inter-ethnic friendships of adolescent students: A Canadian study. International Journal of Intercultural Relations 24, 247-258. 
Song, J. (2000) Rejection, understanding, strategy: Japanese political studies in Korea after the Second World War. Social Science Japan Journal 3 (1), 95-112.

Stephan, W. (1999) Reducing Prejudice and Stereotyping in Schools. New York: Teachers College Press.

Talburt, S. and Stewart, M.A. (1999) What's the subject of study abroad?: Race, gender, and 'living culture'. Modern Language Journal 83 (2), 163-175.

Tawara, Y. (2000) Junior high school history textbooks: Whither 'comfort women' and 'Nanking Massacre'. Sekai [The World] (English translations on-line) 681.

Taylor, D.M. and Moghaddam, F.M. (1994) Theories of Intergroup Relations: International Social Psychological Perspectives. Westport, CT: Praeger.

Terenzini, P., Pascarella, E.T. and Blimling, G.S. (1996) Students' out-of-class experiences and their influence on learning and cognitive development: A literature review. Journal of College and Development 37 (2), 149-162.

Toyokawa, T. and Toyokawa, N. (2002) Extracurricular activities and the adjustment of Asian international students: A study of Japanese students. International Journal of Intercultural Relations 26, 363-379.

Ward, C. (1996) Acculturation. In D. Landis and R.S. Bhagat (eds) Handbook of Intercultural Training (pp. 124-147). Thousand Oaks, CA: Sage.

Ward, C., Bochner, S. and Furnham, A. (2001) The Psychology of Culture Shock. Hove, East Sussex: Routledge.

Wilkinson, S. (1998) Study abroad from the participants' perspective: A challenge to common beliefs. Foreign Language Annals 31 (1), 23-39.

Wilkinson, S. (2001) Beyond classroom boundaries: The changing nature of study abroad. In R.Z. Lavine (ed.) Beyond the Boundaries: Changing Contexts in Language Learning (pp. 81-105). Boston: McGraw-Hill Higher Education.

Wilkinson, S. (2002) The omnipresent classroom during summer study abroad: American students in conversation with their French hosts. Modern Language Journal 86 (2), 157-173.

Yamaguchi, M. (2004) All things Korean now popular in Japan. Guardian Unlimited. Monday, November 22. On WWW at http://www.guardian.co.uk/worldlatest/ story.

Yashima, T., Zenuk-Nishide, L. and Shimizu, K. (2004) The influence of attitudes and affect on willingness to communicate and second language communication. Language Learning 54 (1), 119-152. 